\title{
"A dynamic factor model applied to investor sentiment in the European context"
}

\author{
Pedro Manuel Nogueira Reis (D) https://orcid.org/0000-0003-1301-6645 \\ AUTHORS \\ [R https://publons.com/researcher/1887144/pedro-m-nogueira-reis/ \\ Carlos Pinho (D https://orcid.org/0000-0002-7422-4555 \\ [R https://publons.com/researcher/C-2033-2015
}

ARTICLE INFO

Pedro Manuel Nogueira Reis and Carlos Pinho (2021). A dynamic factor model applied to investor sentiment in the European context. Investment Management and Financial Innovations, 18(1), 299-314. doi:10.21511/imfi.18(1).2021.25

DOI http://dx.doi.org/10.21511/imfi.18(1).2021.25

RELEASED ON

Tuesday, 23 March 2021

RECEIVED ON

Thursday, 18 February 2021

ACCEPTED ON

Friday, 19 March 2021

(c))EY

LICENSE

This work is licensed under a Creative Commons Attribution 4.0 International License

JOURNAL

"Investment Management and Financial Innovations"

ISSN PRINT $1810-4967$

ISSN ONLINE $1812-9358$

PUBLISHER

LLC "Consulting Publishing Company "Business Perspectives"

FOUNDER

LLC "Consulting Publishing Company "Business Perspectives"

NUMBER OF REFERENCES

77
NUMBER OF FIGURES

4
NUMBER OF TABLES

3

(C) The author(s) 2021. This publication is an open access article. 


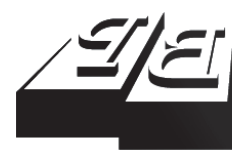

BUSINESS PERSPECTIVES

(O)

LLC "CPC "Business Perspectives" Hryhorii Skovoroda lane, 10, Sumy, 40022, Ukraine www.businessperspectives.org

Received on: $18^{\text {th }}$ of February, 2021 Accepted on: $19^{\text {th }}$ of March, 2021 Published on: $23^{\text {rd }}$ of March, 2021

(C) Pedro Manuel Nogueira Reis, Carlos Pinho, 2021

Pedro Manuel Nogueira Reis, Ph.D. in Finance, Assistant Professor, Polytechnic Institute of Viseu, School of Management, Center for Research in Digital Services (CISeD), Campus Politécnico de Repeses, Portugal. (Corresponding author)

Carlos Pinho, Ph.D. in Applied Economics, Associate Professor, Department of Economics, Management and Industria Engineering and Tourism, University of Aveiro, Portugal.

\title{
A DYNAMIC FACTOR MODEL APPLIED TO INVESTOR SENTIMENT IN THE EUROPEAN CONTEXT
}

\begin{abstract}
This paper proposes an Investor Sentiment Index for the European market and tests its predictability power over returns and volatility. The constructed Investor Sentiment Index for Europe draws upon three well-established and two recent individual sentiment proxies through a novel dynamic factor modeling addressed to behavioral finance. The index is obtained through an extended period of analysis and validated with other sentiment index measures. The work relies on individual sentiment proxies based on a dynamic factor model and tests it using a TGARCH model for volatility and returns. It carries out an in-sample and out-of-sample analysis to examine this sentiment index's forecasting power over returns sustained on a recursive rolling window prediction against Fama and French's three-factor model. The findings demonstrate that the proposed index closely predicts STOXX600 variance and returns and confirms a strong spillover effect between European and US stock markets. This study also concludes that the proposed European Sentiment Index is a valid alternative method for investors to monitor and predict market behaviors. The developed sentiment measure is a vital market prediction movement tool for financial information providers, investors, bankers, and financial analysts. The research combines the sentiment index with a TGARCH approach over the extended period of analysis and validates the method with other sentiment index measures. An in-sample and out-of-sample study confirms the predictive power of this work's sentiment over returns compared to Fama and French's three-factor model.
\end{abstract}

Keywords

JEL Classification

\section{INTRODUCTION}

Investor sentiment can influence decisions by affecting asset prices as they suffer from biases that affect market behavior (Pompian, 2011; Piccione \& Spiegler, 2014; Benhabib et al., 2016; Jitmaneeroj, 2017). Investor emotions partially describe stock market changes, particularly in periods of senseless and unjustified panic or exaggerated optimism. Human emotions such as extreme excitement or fear and perceptive mistakes may generate emotional biases when evaluating the stock market's future performance, provoking peak movements and instability (Reis \& Pinto, 2021). Sentiment may provoke a deviance bias amid asset price obtained by fundamentals and actual price (Giglio \& Kelly, 2017; Zhou, 2018) and cause asset mispricing. Since investor sentiment is not directly visible, academia utilizes proxy measures, potentially carrying a risk of error as sentiments impact asset prices in several degrees. The proxy measure must efficiently capture the corresponding sentiment's essence and strength or scale (Reis \& Pinho, $2020 \mathrm{a})$. The proxy can provide grades of contagion spillover and market co-movements. There have been several academic attempts to measure investor sentiment through market sentiment data, survey data, or text analysis. Despite the extensive literature on the investor sentiment influence on market returns and volatility, only a few of 
them address the construction of a single investor sentiment index sustained on market data and fewer on analyzing the European market (Baker et al., 2012, Reis \& Pinho, 2020, as examples), as defended by Zhou (2018).

Also, sentiment indices for Europe are only based on a few countries' targets, and just one study endorses a globally European countries index (Reis \& Pinho, 2020b). Following these researchers, the paper introduces a European Sentiment Index that aggregates various tested proxy measures for investor sentiment, including two recent individual sentiment proxies: gold and German sovereign bond yields spread between the ten years and the two-year term (Reis \& Pinho, 2020a). This paper's approach is based on constructing a statistical model to understand the stochastic processes describing investor sentiment, thereby applying much rarely explored methods as diffusion indices, also named dynamic factors. Afterward, this work uses a TGARCH model to address volatility and returns, as suggested by Zhou (2018) for future research motivation. The paper conducts an in-sample and out-of-sample analysis to test this study's sentiment indices predictability power on European results and examine it with the 3-factor Fama and French model. This study's originality arises from the application of Dynamicfactor models intended to multivariate time series where unobserved factors display an autoregressive vector structure, and exogenous covariates are allowable in the latent factors' equations and the observable dependent variables equations (Statacorp, 2019). Lutz (2016) applied this modeling structure to build an investor sentiment index for the US's lottery-stocks.

Moreover, the paper models market volatility with a TGARCH approach and studies the spillover effect between the European and the US market. Also, the investor sentiment index developed in this paper is compared with the Baker and Wurgler (2006) and Reis and Pinho (2020b) index. The rest of the paper is organized as follows: Section 1 contains a literature review, followed by methods, then the results are presented, and the last section provides a conclusion.

\section{LITERATURE REVIEW}

Feelings like belief, uncertainty, joy, or distrust that investors sense concerning firms' performance expectations significantly affect financial market behavior. It may be a feeling, judgment, or opinion supported by a thought about a situation or even a rational mode about something. Investor sentiment as an unobservable variable affects asset returns ahead of company fundamentals or macroeconomic circumstances. This topic has been a target of long debates considering the matters related to its measurement and its forecasting ability on market crashes and bubbles or spillovers amongst financial markets.

Zhou (2018) defends that the investor sentiment measurement has been strongly discussed by academia. Sentiment measures that coexist today are related to market data, survey or questionnaire data, and text/media analysis data, and research debates what is the best measure of proxy sentiment and forecasts market movements and co-movements.
Measures based on market data analysis included trading volumes and were applied by several works (Ma et al., 2018; Seok et al., 2019; Zhou, 2018; Zhou \& Yang, 2019; Anusakumar et al., 2017; Ryu et al., 2017; Gao \& Yang, 2017; He et al., 2017). Market volatility was also considered as a proxy measure for sentiment, as Jitmaneeroj (2017), and Rehman and Apergis (2019) testify. The closedend discount funds considered as a predictor of future market evolution as it measures the future sentiment related to the evolution of equities was one of the most relevant individual measures of sentiment as numerous articles demonstrate (Lee et al., 1991; Baker \& Wurgler, 2006, 2007; Baker et al. 2012; Huang et al., 2015). The dividend premium, an indicator that accounts for the potential market optimism, is also an important indicator for individual investor sentiment used by Baker and Wurgler $(2006,2007)$, Huang et al. (2015), Ma et al. (2018), and Zhou (2018). The IPO number and IPO first-day returns average when they have high values indicate market optimism, and they are often employed in research (Baker \& Wurgler, 2006, 2007; Kumari \& Mahakud, 2015; 
Dash, 2016; Asem \& Tian, 2016; Ma et al., 2018; Zhou, 2018). The relative strength index (RSI) consists of a technical analysis indicator screening the market accumulated movement of a share and potentially depicts a future sentiment trend, which was the target of some research (Ryu et al., 2017; Seok et al., 2019; Zhou \& Yang, 2019). The ratio of advance issues to declining issues per day indicates a market sentiment and thus is a sentiment indicator (Dash, 2016; Brown \& Cliff, 2004; Jitmaneeroj, 2017; He et al., 2017) as the buy and sell imbalance ratio (Gao \& Yang, 2017; Kumari \& Mahakud, 2015; Tsai, 2017). The put-call ratio is an important indicator that translates into the market's bet that equity option investors are doing concerning the market's prospects. Different studies have applied this indicator to measure investor sentiment (Kumari \& Mahakud, 2015; Dash, 2016; Brown \& Cliff, 2004). A standard sentiment indicator of all market is the VIX or volatility index and is often applied in research (Lutz, 2016; Brown \& Cliff, 2004; Smales, 2017).

In the USA, measures based on surveys and inquiries are exemplified by the University of Michigan Consumer Sentiment Index, the State Street Investors Confidence Index, the Investors Intelligence, the American Association of Individual Investors (AAII), and the UBS/ GALLUP Index for Investor Optimism as defended by Jitmaneeroj (2017) and Brown and Cliff (2004). In Europe, the most relevant examples are the EUROSI (Eurozone Sentix Indicator; Debata et al., 2018), the Consumer Confidence Index, and the Economic Sentiment Indicator. Zouaoui et al. (2011), Qiu and Welch (2006), Schmeling (2009), Beer et al. (2018), Ho and Hung (2012), Fernandes et al. (2013), and Ho and Hung (2009) applied a consumer sentiment index in their analysis as a proxy for investor sentiment, while Simões (2011), Ho and Hung (2012), Fernandes et al. (2013) and Chiu et al. (2018) used an Economic Sentiment Indicator.

Finally, text data indicators are derived from collecting several words from media sources such as Facebook, Twitter, Instagram, Google, LinkedIn, journals, magazines, and websites such as Bloomberg, CNBC, and Reuters (Loughran \& Mcdonald, 2016; Da et al., 2015, Gao et al., 2020). Most of the cited studies build their investor sen- timent measures using just one or a few individual proxies and may be subject to a simplification proxy error. An investor sentiment composite index containing a full length of individual proxy measures may produce better results when predicting market behavior.

Some studies address the construction of investor sentiment indices, mainly using text data, but few utilizing market data measures.

\subsection{Investor sentiment indices}

In this context, the global investor sentiment index, based upon six sentiment individual proxy measures proposed by Baker and Wurgler (2006), is widely seen as a preferred approach, considering that it is commonly referenced and used in several behavioral finance studies (Chen et al., 2010; Huang et al., 2015; Yang \& Zhou, 2015, 2016; Kumari \& Mahakud, 2015; Lutz, 2016; Asem \& Tian, 2016; Jitmaneeroj, 2017; He et al., 2017; Gao \& Yang, 2017; Ma et al., 2018).

Concerning investor sentiment indices targeting countries outside Europe, and in addition to the Baker and Wurgler (2006) index, Chen et al. (2010) implemented a sentimentality measure for emerging markets using principal component analysis (PCA) for US and Japan markets. Also, Reis and Pinho (2020b) refer that Huang et al. (2015) announce that partial least squares (PLS) can be used to attain a reliable investor sentiment index for evaluating the equity risk premium for US markets. Yang and Zhou (2016) promote sentiment index at the firm-level that also requests PCA. Kumari and Mahakud (2015) introduce a sentiment index to emerging stock markets. Later on, Lutz (2016) advanced an investor sentiment index by estimating a latent factor exploiting a dynamic factor model by incorporating lottery-like stocks' returns.

Considering the Investor sentiment indices scoping European markets, Baker et al. (2012) have developed one sustained on data for Canada, Germany, France, the United Kingdom, Japan, and the United States, including three European countries. Corredor et al. (2013) create investor sentiment indices for France, Spain, Germany, and the United Kingdom, using Baker and Wurgler's 
(2006) method. However, they employ volatility, share turnover, and the Consumer Confidence Index as single sentiment proxies. The researchers conclude that investor sentiment influences stocks' future returns that are difficult to price, more expensive and riskier to arbitrage. The results' sensitivity depends on the sentiment index and is prone to country-specific features. Reis and Pinho (2020b) built a European investor sentiment index based on a modified Baker and Wurgler (2006) method and different individual investor sentiment proxy constituents, concluding a strong predicting power of their index on stock returns.

This paper constructs a statistical model that seeks to understand the stochastic processes describing investor sentiment, applying much rarely explored methods as diffusion indices, also named dynamic factors. Addressing volatility and returns with a TGARCH model, this paper builds and tests a sentiment index sustained on the referred Dynamic Factor Model. Then it trials its predictive power on European returns and volatility, comparing it with other market sentiment indices and supplying further robustness tests through an in and out-of-sample analysis against the 3-factor Fama and French model.

\section{METHODS}

\subsection{Sentiment proxies' variables}

Table 1 presents the variables in this study's model and summarizes descriptive statistics. The paper used the consumer confidence index, gold bullion price, economic sentiment, the VSTOXX volatility index, and the German spread between the 10th and the 3rd year government yield as this paper's European investor sentiment proxies as applied in the Reis and Pinho (2020b) work. Reis and Pinho (2020a, 2020b) tested these two last measures with good results, and thus, this paper considers they may influence a broader sentiment index. Gold stands as a haven for major European stock markets, acting as a soothing strength in the markets, as Baur and McDermott (2010) and Reis and Pinho (2020a) stated. Investors developed a more risk-aversion profile in times of adverse sentiment searching for safe assets like bonds from countries with low default risk, such as Germany (Bolton \&
Jeanne, 2011; Gómez-Puig et al., 2014). If the yield curve overturns and short-term sovereign interest rates are more significant than long-term sovereign yield rates, investors opt for the trade-off of lower rates but longer terms. Stoxx600 is the stock index applied for log return calculation, with the Baker and Wurgler (2006) and Reis and Pinho (2020b) sentiment indices serving for comparison.

\subsection{Macroeconomic variables}

The paper defined a dummy variable like NBER (National Bureau of Economic Research recession indicator) using EUROREC, the OECD- Recession Indicator for Euro Area. OECD identifies months representing turning points, and a dummy variable conventionally represents that event. Dummy variables assume a value of zero in periods of expansion and one of recession periods. This work controlled the effects of many macroeconomic aggregates (GDP growth, population growth, exports of goods and services dividing by the GDP, and inflation rate) on the sentiment proxies (Reis $\&$ Pinho, 2020b).

\subsection{Statistical analysis}

The paper applied two statistical methods. The first one, dynamic factor modeling (DFM), extracts a common factor from the set of all sentiment proxies, and the second applies the common factor to estimate data on returns and volatility. Before dynamic factor estimation, this work used macroeconomic variables and removed the macro-effects from the single sentiment proxies to orthogonalize them. This paper regressed each proxy variable against the macroeconomic variables to extract systematic risk through OLS (ordinary least squares). The standardized residuals (mean $=0$, and variance $=1$ ) are widely seen as the most proper proxies for the sentiment, as also applied by Baker and Wurgler $(2006,2007)$ and Reis and Pinho (2020b). Dickey-Fuller test assessed whether the series had unit root or were stationary as required for all variables. Then the paper proceeded to dynamic factor modeling.

Afterward, this paper conducts an in-sample and out-of-sample analysis using a benchmark of the three-factor model created by Fama and French to test if this study's sentiment measure better pre- 
Table 1. Descriptive statistics and definition of variables

Source: Monthly data from January 1999 to July 2019.

\begin{tabular}{|c|c|c|c|c|c|c|}
\hline Variable & $\begin{array}{l}\text { No. of } \\
\text { observ. }\end{array}$ & Mean & STD & Min, Max & Type & Data source \\
\hline $\mathrm{CCl}$ & 546 & 100.15 & 0.84 & $97.63,101.78$ & Proxy for sentiment & $\begin{array}{c}\text { https://data.oecd.org/leadind/ } \\
\text { consumer-confidence-index-cci.htm }\end{array}$ \\
\hline ESI & 414 & 100.91 & 9.67 & $65.20,116.80$ & Proxy for sentiment & $\begin{array}{l}\text { https://ec.europa.eu/info/business- } \\
\text { economy-euro/indicators-statistics/ } \\
\text { economic-databases/ }\end{array}$ \\
\hline VSTOXX & 247 & 23.74 & 8.83 & $11.98,61.33$ & Proxy for sentiment & $\begin{array}{l}\text { https://www.stoxx.com/ } \\
\text { index-details?symbol=V2TX }\end{array}$ \\
\hline gold & 559 & 487.71 & 332.42 & $66.6,31380.50$ & Proxy for sentiment & Datastream \\
\hline german spread & 382 & 0.82 & 0.63 & $-0.94,2.07$ & Proxy for sentiment & Construction \\
\hline $\begin{array}{l}\text { exp.goods over } \\
\text { gdp }\end{array}$ & 552 & 31.22 & 7.07 & $20.76,44.73$ & Macroeconomic & Datastream \\
\hline GDP & 552 & 2.12 & 1.62 & $-4.34,6.10$ & Macroeconomic & Datastream \\
\hline pop. growth & 552 & 0.30 & 0.11 & $-0.06,0.59$ & Macroeconomic & Datastream \\
\hline inflation & 552 & 4.85 & 3.51 & $-0.05,13.64$ & Macroeconomic & Datastream \\
\hline Eurorec & 557 & 0.40 & 0.49 & 0,1 & Macroeconomic & $\begin{array}{c}\text { https://fred.stlouisfed.org/series/ } \\
\text { EUROREC }\end{array}$ \\
\hline STOXX600 & 392 & 255.12 & 130.97 & $68.54,553.51$ & Europe Market index & https://investing.com \\
\hline BWsentiment & 552 & 0 & 0.88 & $-2.42,3.19$ & $\begin{array}{c}\text { Comparable Investor } \\
\text { Sentiment Index }\end{array}$ & http://people.stern.nyu.edu/jwurgler/ \\
\hline finalpc1 & 239 & 0 & 1 & $-3.90,2.512$ & $\begin{array}{l}\text { Comparable Investor } \\
\text { Sentiment Index }\end{array}$ & (Reis and Pinho, 2020b) \\
\hline
\end{tabular}

Note: $\mathrm{CCl}$ is the Consumer confidence index $(\mathrm{CCI})$ for Europe; $\mathrm{ESI}$ is the Economic Sentiment Indicator (ESI) for Europe: VSTOXX - the VSTOXX Indices built on EURO STOXX 50 real-time options prices. It is the European Fear gauge index based on equity options trading (American VIX); gold is the Price of gold bullion per Oz in EUR; german spread is the German bond yield difference from 10-year and 3-year term; exp.goods over GDP is the Export of goods and services over GDP; GDP is the Gross domestic product in Europe; pop. Growth is the Population growth in Europe; inflation, the Consumer price index for Europe; Eurorec is the OECD Recession Indicators for Euro Area; STOXX600 - the Logarithm market return of Stoxx600; BWsentiment the Investor sentiment index of Baker and Wurgler (2006), and finalpc1 is the Investor sentiment index (Reis \& Pinho, 2020b).

dicts the European returns over a recursive rolling window of 50 months and an out-of-sample as of 2012 till July 2019.

\subsection{Dynamic factor models}

Dynamic factor models (or diffusion indexes) are simulations for multivariate time series where unobserved factors display an autoregressive vector structure, and exogenous covariates are allowable both in the latent factors' equations and the observable dependent variables equations (Statacorp, 2019). They were originally recommended by Geweke (1977) as a time-series addition of factor models established for cross-sectional data. The main advantage of the approach is that a small number of factors can explain a large fraction of variance in many financial series (Stock \& Watson, 2011). Another advantage is that if disturbances in equations 1 and 2 (see below) show a Gaussian distribution, efficient forecasts can be obtained by regressing the variable of interest on the lagged factors and the variable lags (Stock \& Watson, 2011).
Consequently, the models rely on a few factors substituting for a usually much larger number of variables.

Additionally, errors in the equations for dependent variables might be autocorrelated. The DFM betas of dynamic-factor models are obtained by maximum likelihood using the stationary Kalman filter (De Jong, 1991) and the De Jong (1988) diffuse Kalman filter. Accordingly, dynamic factor models extract a mutual component from a set of time series. Dynamic factor models have been frequently applied in macroeconomics (Stock \& Watson, 1989, 1998; Watson \& Engle, 1983; Reijer, 2013; Stock \& Watson, 2002), but rarely in behavioral finance, with a single study on the American market (Lutz, 2016).

This paper assumes that the individual sentiment proxies reflect a common dynamic explaining factor:

$$
X_{t}=\partial X_{t-1}+\wedge F_{t}+\varepsilon_{t}
$$


where $X_{t}$ is an $\mathrm{nx} 1$ vector of investor sentiment proxies orthogonalized with macro variables (Table 1), its first lag $\partial$ is a matrix of sentiment proxy loadings, $\wedge$ is a matrix of the loadings of the factor of dimension nxk $F_{t}$ is a kxl vector of period specific factor loadings, and $\varepsilon_{t}$ is an $\mathrm{nx} 1$ vector of measurement errors.

The dynamic factor model assumes factors with a dynamic autoregressive form:

$$
F_{t}=\phi(L) F_{t-1}+\mu_{t}
$$

where $\phi(L)$ is a lag polynomial that describes the autoregressive structure of the data-generating process, and $\mu_{t}$ represents the error. The extracted factor is then standardized to mean 0 and variance 1 . After reducing explanatory variables to a single factor, the next step is the prediction of returns and volatility following the methodology of Stock and Watson (1991, 2002), Lutz (2016), and Statacorp (2019).

\subsection{Threshold autoregressive conditional heteroskedasticity}

This work applied a threshold autoregressive conditional heteroskedasticity model (TGARCH) as in the works of Aydogan (2017) and Rupande et al. (2019), which assumes that extended high volatility periods are tailed by other high unpredictability periods, while low volatility periods are followed by other low volatility periods (cluster volatility). Consequently, the error term is conditionally heteroscedastic and susceptible to representation by an ARCH (autoregressive conditional heteroskedasticity model), GARCH (generalized autoregressive conditional heteroskedasticity model), or TARCH (threshold autoregressive conditional heteroskedasticity model). Therefore, this paper model includes two equations: the ARCH mean equation (3) and the volatility equation (4):

$$
\begin{aligned}
& y_{t}=\beta_{0}+\beta_{1} y_{t-1}+\beta_{2} y_{t-2}+ \\
& +s t d f_{t}+s t d f_{t-1}+\mu_{t},
\end{aligned}
$$

where $y_{t}$ is the log of the STOXX600 return, with a one and two period lag form as an independent variable along with the level and the one-period lag of this work's standardized sentiment factor $(s t d f)$, obtained by dynamic factor modelling according to equations (1) and (2), and $\mu_{t}$ represents residuals.

The equation for the conditional variance of stock returns index at time $t$ with an $\mathrm{ARCH}, \mathrm{GARCH}$ and TGARCH effect is:

$$
\begin{aligned}
& \sigma_{t}^{2}=\theta+\sum_{i=1}^{p} \vartheta_{i} \mu_{t-i}^{2}+\varphi \mu_{t-1}^{2} d_{t-1}+ \\
& +\sum_{j=1}^{q} \omega_{j} \sigma_{t-j}^{2}+\exp ^{\delta F_{t-1}}
\end{aligned}
$$

where $\sigma_{t}^{2}$ is the stock returns variance, $\vartheta_{i}$ is the ARCH effect representing the impact of the mean equation squared residual on actual variance, or once past information had an effect on share return variance, and $\omega_{j}$ is the GARCH effect computing the effect of historical volatility on current volatility of stock returns, $d_{t-1}$ is a dummy variable with the value of 1 when $\mu<0$ (negative news) and the value of 0 when $\mu>0$ (positive news), $\varphi$ is the TGARCH or leverage effect, and the positive value of its coefficient appoints that negative news rises upcoming volatility greater than positive news. The leverage effect term returning a negative sign shows that positive shocks have larger effects on the next period volatility than damaging shockwaves of the same sign or magnitude. Sudha (2015) argues that a measure of $\vartheta_{i}+\omega_{j}$ very close to unity proves both short-run and long-run persistent volatility. The volatility expression holds regressors to deal with a structural part of volatility denoted as multiplicative heteroskedasticity (HET). This work includes the dynamic factor $F$ (stdf in this paper's model) with its effects represented by the $\delta$ coefficient as defined by Judge et al. (1985) and Statacorp (2019). The work assumed a Gaussian distribution for all estimations. This paper's model used the condition of one ARCH term, so that equation (4) simplifies to $i=1$ and $j=1$. The prerequisites for $\mathrm{ARCH}$ effects in the mean equation require the absence of serial correlation, heteroscedasticity, and ARCH effects in the return residuals. This paper applied the Breush-Godfrey LM test for residual correlation (Breusch, 1978; Godfrey, 1978), the White test for heteroscedasticity (1980), and the Engle ARCH LM test (1982) for ARCH effects, as also applied by Reis and Pinho (2020b). After estimating the 


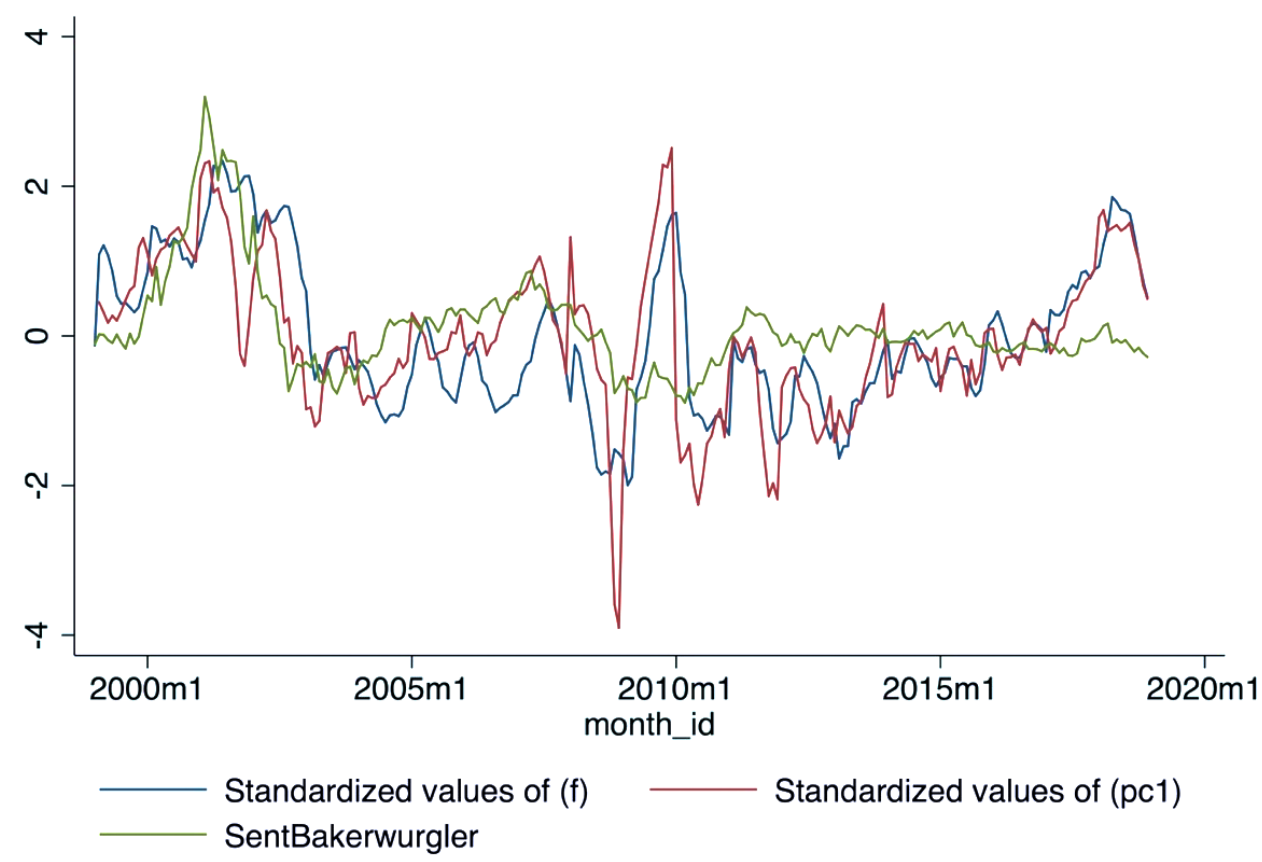

Figure 1. Comparison of standardized values of the proposed European sentiment index, standardized values of pc1 or EURsent index (Reis \& Pinho, 2020b), and standardized values of US sentiment index (Baker \& Wurgler, 2006)

model, this paper assessed the residuals and ensured the avoidance of serial correlation. The work then ran the Toda and Yamamoto (1995) and the Dolado and Lutkepohl (1996) causality tests, a modified Wald test for Granger causality that does not rely on a prior cointegration test, to assess whether this paper's measure of sentiment causes returns. Next, this paper predicted variance and after standardization, it was compared and correlated with other investor sentiment in- dex measures proposed by Baker and Wurgler (2006) and Reis and Pinho (2020b).

\section{RESULTS}

Table 2 shows the joint estimation of the mean equation and volatility equation through $\mathrm{ARCH}$, GARCH, and TGARCH effects, and the effect of stdf on the two equations. Only significant variables are shown.

Table 2. TGARCH model for log of Stoxx600 return and volatility

\begin{tabular}{|c|c|}
\hline Mean equation & Coefficient (and $t$ statistics) \\
\hline \multirow{2}{*}{$\mathrm{L}_{1} \cdot$ logret 600} & $-0.351^{* *}$ \\
\hline & $(-2.64)$ \\
\hline \multirow{2}{*}{$\mathrm{L}_{1} \cdot \mathrm{stdf}$} & $-0.0306^{*}$ \\
\hline & $(-2.33)$ \\
\hline Variance equation & \\
\hline \multirow{2}{*}{$\mathrm{L}_{1} . \mathrm{stdf}$} & $0.437^{*}$ \\
\hline & $(2.07)$ \\
\hline \multirow[b]{2}{*}{ _cons } & $-7.871^{* * *}$ \\
\hline & $(-18.38)$ \\
\hline \multirow{2}{*}{$\mathrm{L}_{1} \cdot \operatorname{arch}$} & $0.250^{*}$ \\
\hline & $(2.37)$ \\
\hline \multirow{2}{*}{$\mathrm{L}_{1} \cdot \operatorname{tarch}$} & $-0.242^{*}$ \\
\hline & $(-2.36)$ \\
\hline \multirow{2}{*}{$\mathrm{L}_{1}$.garch } & $0.713^{* * *}$ \\
\hline & $(7.21)$ \\
\hline $\mathrm{N}$ & 239 \\
\hline
\end{tabular}

Note: Sample period: July 1999 - April 2019. Sample size: $239{ }^{*} p<0.05, * * p<0.01, * * * p<0,001$. Wald Causality test chi2(5) $=16.87$. Prob $>$ chi $2=0.0048 ; L_{1}$. means one lag. 


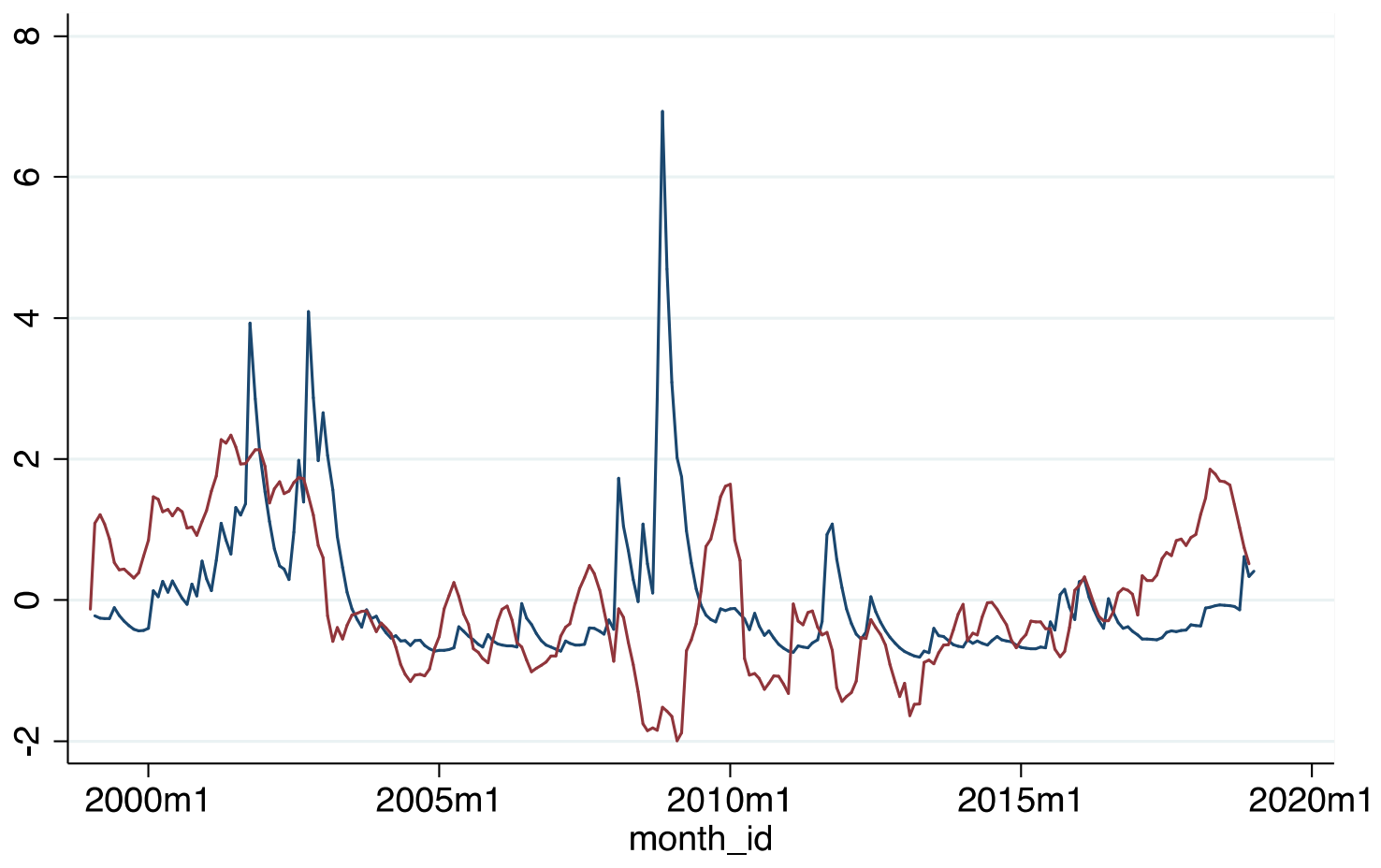

Standardized values of (variance_3) - Standardized values of (f)

Figure 2. Standardized Stoxx600 returns variance obtained from the ARCH model and standardized sentiment index (stdf)
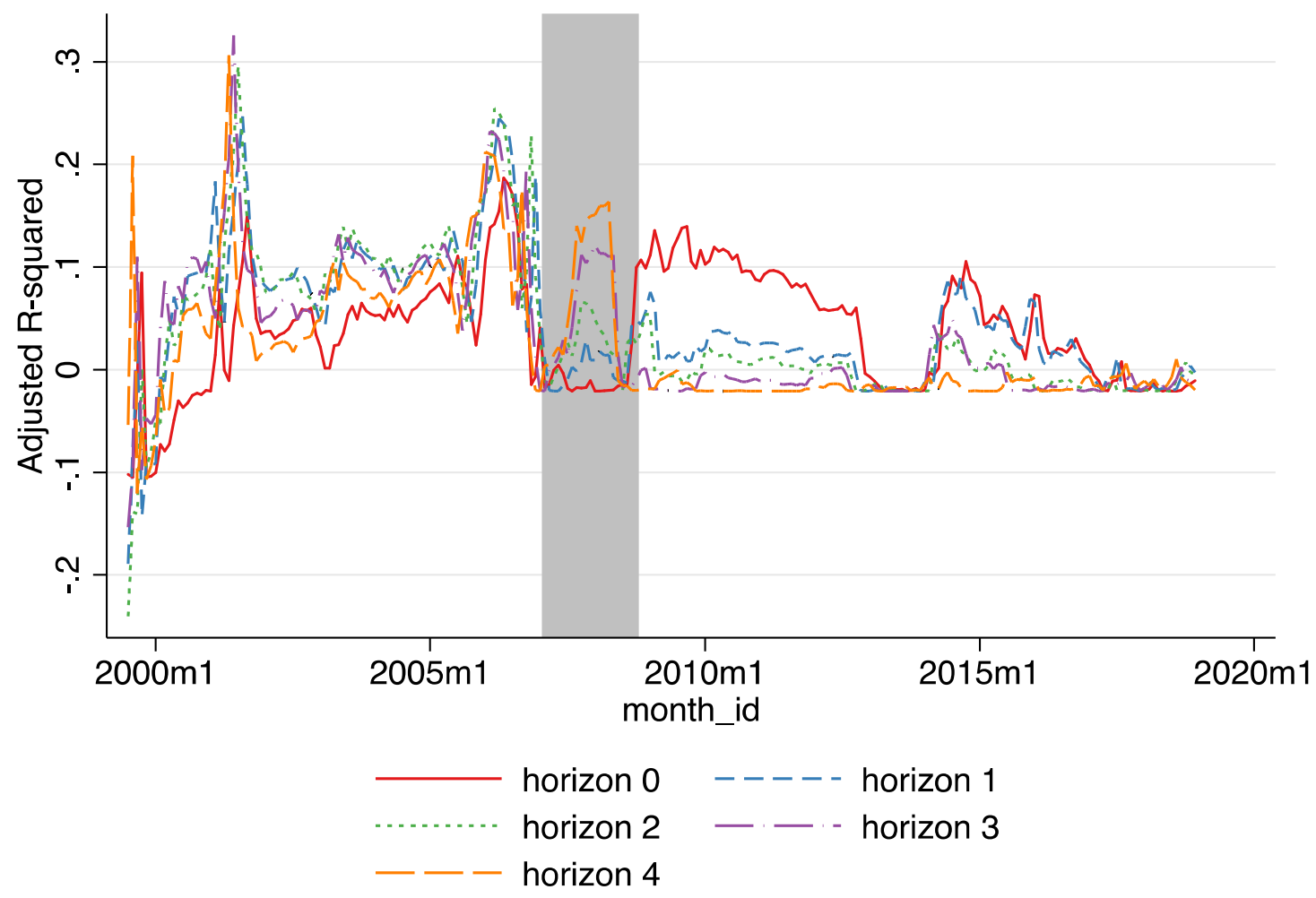

Note: The shaded area is the subprime crisis period.

Figure 3. The adjusted R2 for a 50-month rolling window returns forecast from 1999-2018, for horizons 0 to 4 with Newest t statistics 

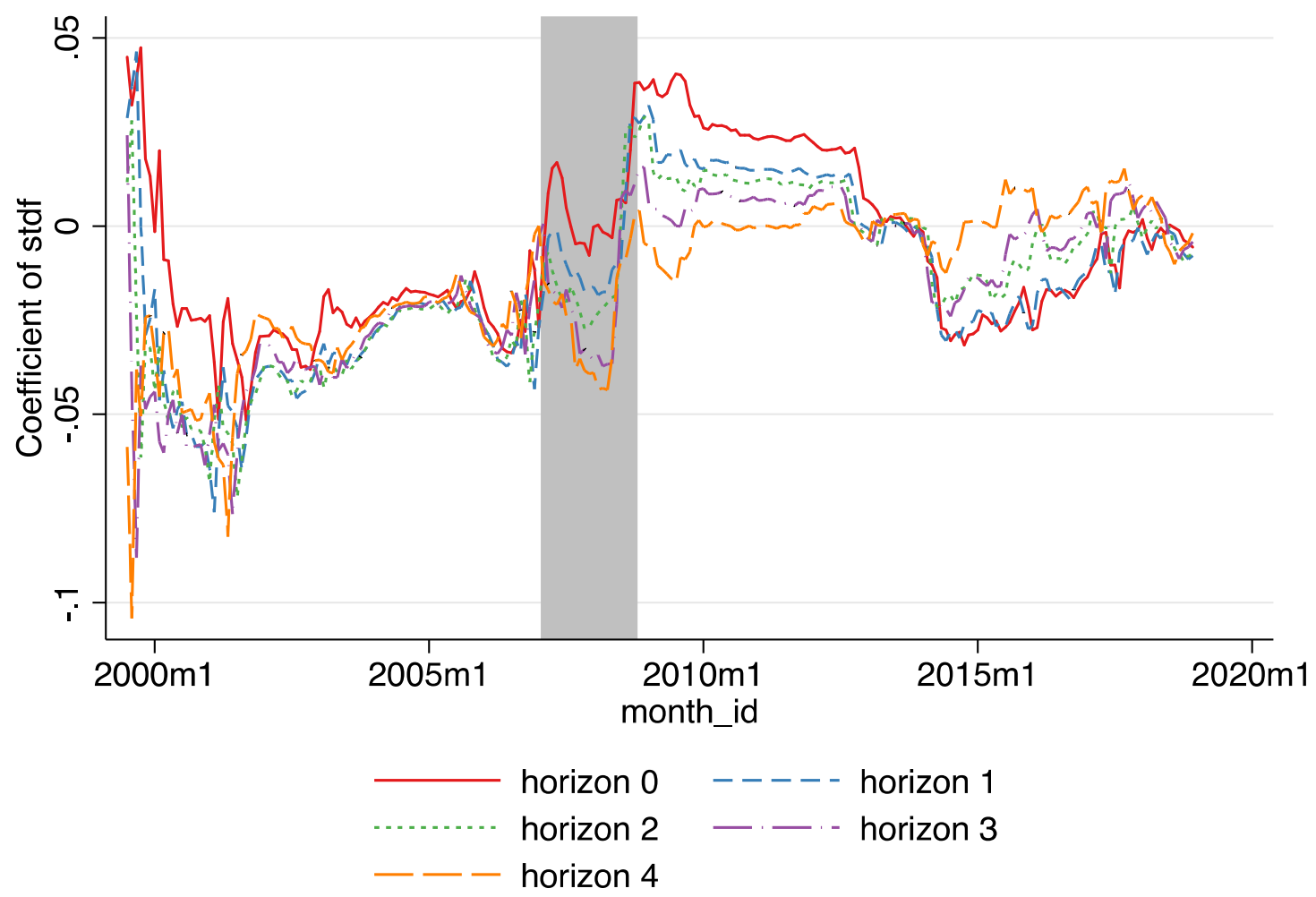

Note: The shaded area is the subprime crisis period.

Figure 4. The sentiment coefficient for a 50-month rolling window returns forecast from 1999-2018, for horizons 0 to 4 with Newest t statistics

Table 3. Out-of-sample forecasting results

\begin{tabular}{c|c|c|c}
\hline Forecast period & $\mathbf{R}_{\text {oos }} \mathbf{( \% )}$ & $\mathbf{R 2}_{\text {oos rec }} \mathbf{( \% )}$ & $\mathbf{R}_{\text {oos exp }}$ (\%) \\
\hline 1 & $4.76 \%$ & $-0.18 \%$ & $5.82 \%$ \\
\hline 2 & $2.73 \%$ & $-0.04 \%$ & $5.49 \%$ \\
\hline 3 & $3.64 \%$ & $3.44 \%$ & $3.08 \%$ \\
\hline 4 & $3.72 \%$ & $1.62 \%$ & $4.31 \%$ \\
\hline
\end{tabular}

Note: Table 3 reports the out-of-sample forecasts for the periods from one to four months ahead the monthly excess European market return using this paper's sentiment index. The out-of-sample predictions are projected on a 60-month rolling recursive window and the forecast formation at time t. $\mathrm{R}^{2}$ oos is calculated according to the Campbell and Thompson (2008) out-of-sample computing the reduction in mean square errors (MSFE) for the model under evaluation compared to the benchmark model. $\mathrm{R}^{2}$ and $\mathrm{R}^{2}$ sos statistics are calculated with the EUROREC recession indicator for the Euro Area. Benchmark model is the 3-factor model of Fama and French for the European market returns from 1999 to July 2019. The model under evaluation includes this study's sentiment index. The out-of-sample evaluation period is 2010M1-2019M07.

\section{DISCUSSION}

\subsection{TGARCH analysis}

The estimated $s t d f$ factor exhibited a high Pearson correlation of $r=0.71$ with the index by Reis and Pinho (2020b), and a positive correlation of $r=$ 0.44 with the index by Baker and Wurgler (2006) (Figure 1), which highlights the importance of market co-movements and contagion, as well as potential spillovers between European and US markets. Before the global funding crisis (2007), the correlation between the stdf sentiment index and Baker and Wurgler's index was $r=0.56$, but almost absent afterward, while the correlation between this work's index and Reis and Pinho's index for Europe remains almost the same. This paper's DFM resulting index is flatter in periods of high optimism or high pessimism, as observed between 2007 and 2010.

This study stdf factor closely tracks the main events causing instability in stock markets. After 2001, the dot.com or technology bubble bursting, 
and the terrorist attacks in the US caused great pessimism and led to the lowest stock market levels. The period between 2007 to 2009 corresponded to the subprime crisis followed by the government sovereign debt crisis, and this work's index was able to capture the lowest sentiment level ever seen in the years covered by the sample and the following period of recovered optimism until 2019.

Table 2 presents the TGARCH, GARCH, ARCH, and sentiment (stdf) effects on volatility and log Stoxx600 return. The mean equation (3) produced a $\mathrm{P}(\mathrm{chi} 2)=0.3925$, and, thus, this work cannot reject the null hypothesis of no serial correlation in the Breush-Godfrey test. The mean equation also implies that the series is heteroskedastic as the Lagrange-Multiplier test produces a $\mathrm{P}(\mathrm{chi} 2)<$ 0.0001 ), thereby demonstrating the presence of $\mathrm{ARCH}$ effects. Accordingly, the paper applies TGARCH to model Stoxx600 variance. Table 2 shows that this paper's sentiment measure stdf has a negative correlation with returns (with causality power according to modified Wald test, Prob $>$ chi $2=0.0048)$, confirming previous analyses by Baker and Wurgler (2006), Wenjie Ding et al. (2018), Iyer and Harper (2017), Huang et al. (2015), Lutz (2016), Rupande et al. (2019), and Reis and Pinho (2020b). After the periods of excessive optimism, European market returns decrease. Investors pay less attention to fundamentals in periods of euphoria and can buy at higher prices. On the opposite way, during periods of fear and negativity, investors are more cautious and build their portfolios on a more rational basis, underlying the risk-return principle's importance.

A measure close to unity of $\vartheta_{i}+\omega_{j}$ represented by the ARCH (l.arch) and GARCH (lgarch) coefficients in Table 2, demonstrates both short-run and long-run persistent volatility (Sudha, 2015), which confirms respectively that past information and historical volatility have a substantial effect on contemporary volatility, as well as highlight the presence of cluster volatility in European markets.

The TGARCH-M mean equation shaped as an ARMA (1.1) resolves any potential issues related to autocorrelation in the mean equation. The outcome shows that the ARMA (1.1) coefficient is statistically significant $(P<0.001, t$-value $=$ 3.67, which implies that STOXX600 returns are explained by their historical values, indicative of momentum and mean reversion in share trading as well as past unanticipated shocks, confirming the analyses by Rupande et al. (2019). This result may indicate that the effect of historical returns and historical shocks on the conditional mean may disappear afterward a brief period.

Positive and negative news have diverse grades of influence on stock market volatility. The evidence for such unequal effects (or the leverage effect captured by the TARCH coefficient) suggests that negative news has a much stronger effect on volatility than positive news of the same size. Ho et al. (2013) applied two-family GARCH models to demonstrate that specific news sentiments have a daily impact on volatility and volatility persistence, and showed that negative news has a more substantial impact on volatility than positive news. Kumari and Mahakud (2015) also applied a VAR-GARCH model and concluded that negative investor sentiment, predominantly from retail investors, causes high volatility in US markets. Sayim and Rahman (2015) argued that, in general, investors have optimistic expectations about the economy and market fundamentals, which results in positive expectations, reduction of uncertainty, and lower volatility of stock returns. Baker and Stein (2004) also concluded that pessimistic investor sentiment accelerates equity liquidness evaporation and strengthens the selling force during a financial crisis, suggesting a negative mental bias on liquidness and investor trading comportment.

Furthermore, the model developed in this paper revealed a noteworthy positive association between sentiment and volatility (with causality power according to modified Wald test, Prob $>$ chi2 $=$ 0.0048), with the negative TARCH coefficient, implying that the leverage effect is more noticeable in periods of positive news, thus resulting in periods of high volatility. This paper's results disagree with some published studies. However, they agree with many others, including Sudha (2015), Lee et al. (2002), and Aydogan (2017), with the latter showing a positive liaison between sentiment and variance in Italy and Turkey based on the consumer confidence as their single proxy measure for the sentiment. Moreover, Kling and Gao (2008) and Kumari and Mahakud (2015) estimated a positive sentiment parameter in the variance equa- 
tion. Bahloul and Bouri (2016) also obtained positive correlations between sentiment and volatility. Periods of festive investor mood may drive more prominent stock price fluctuations characteristic of cluster volatility, thereby attracting retail investors more prone to sentiment shifts. Retail investors are willing to pay more, and high fluctuation in prices can therefore promote stock rally periods.

In Europe, institutional investors (Louche \& Lydenberg, 2006) are more rational, more patient, and more prone to making investment decisions based on fundamentals rather than sentiment. This view is confirmed by Labidi and Yaakoubi's (2016) suggestion that aggregate volatility risk is an autonomous risk factor during negative sentiment periods. During optimistic periods, the association amid aggregate volatility risk and predicted returns is fainter due to sentiment-led agents' superior involvement. In times of pessimism and fear, when more rational traders prevail, prices include a premium that considers market volatility.

If this work subdivides the analysis period (Figure 2), from 1999 to 2006, it observes a strong Pearson correlation of $r=0.61$ between sentiment and variance. During the subprime and sovereign crisis (2007 to 2009), there is a clear negative correlation of $r=-0.53$, and from 2010 onwards, a positive correlation of $r=0.28$. Therefore, the sentiment index developed in this study can capture the strength of market variance in returns during the various crises and rank the severity of stock market crises. As in the 2007-2009 period, intense world crises associated with generalized panic generate more significant market variance and instability. High sentiment and market recoveries stimulate higher variance and related volatility, creating uncertainty in markets, demonstrating the asymmetric sentiment effect.

During sentiment peak periods, low sentiment increases uncertainty, reduces liquidity, induces sentiment-led retail traders to leave the market, and strongly attracts rational investors. Alternatively, high volatility is caused by high sentiment during averaged sentiment periods, mainly in rally periods, where periods of good news support higher volatility characterized by irrational retail investors joining the market and broadening price fluctuations. Differences between this paper's results and other studies conducted in other countries and regions may result from using the index instead of single sentiment proxy measures, using past autoregressive values of sentiment based on an index built upon market data instead of sentiment measures based on text collection or surveys, and using a stock index to study global European markets.

\subsection{Forecasting European excess market returns 1999-2018, robustness test, and out-of- sample analysis}

The sentiment indicator is a precise predictor of returns in the European environment during different forecast horizons and under a rolling window of 50 months in an in-sample analysis. With a healthy return explanation power as per the relevant $R^{2}$ and significant coefficient (Figures 3 and 4), this paper's sentiment index captures the latent factor of irrational behavior.

Furthermore, this paper conducts an out-of-sample analysis following the methods of Campbell and Thompson (2008), applied by Huang et al. (2015), Papapostolou et al. (2016), and Han and Li (2017), to test the accuracy of the forecasting power in an out-of-sample context.

To evaluate the forecast accuracy of this work's sentiment index on returns, this paper uses the out-of-sample $R^{2}$ statistic, $R^{2}{ }_{\text {oos }}$, defined by Campbell and Thompson (2008) as:

$$
R_{\text {oos }}^{2}=1-\frac{M S F E^{\text {Model }}}{M S F E^{\text {Benchmark }}},
$$

where $M S F E^{\text {Model }}$ is the mean of squared forecast errors (MSFE) of a forecast model under evaluation, and $M S F E^{\text {Benchmark }}$ is the MSFE of the benchmark.

Table 3 reports an out-of-sample analysis using the 3-factor Fama and French model to compare the Fama and French model versus the same model with the sentiment index developed in this work. The out-of-sample forecasts are appraised on a 60 -month rolling recursive window and the forecast formation at time $t$. The $R_{\text {oos }}^{2}$ is the Campbell 
and Thompson (2008) out-of-sample $R^{2}$ calculating the decrease in mean square errors (MSFE) for the model under estimation compared to the benchmark model. $R_{\text {oosrec }}^{2}$ and $R_{\text {oosexp }}^{2}$ statistics are calculated with the EUROREC recession indicator for the Euro Area. Results reveal a strong out-of-sample predicting power of this paper's sentiment index for the 1 to 4 month's forecast periods ahead. The results are expressive mainly on expansion periods.

When sentiment is small, forthcoming stock returns increase, which is valid for many upcoming monthly periods. While investors are pessimistic and frightened, they are more disposed to reasonableness, and thus institutional investors enter the market when retail investors leave. These investors buy at low prices, select high growth stocks and stocks that pay high dividends, and decide upcoming positive stock market earnings. This conclusion is also understated by Baker and Wurgler (2006, 2007) for the American market, and Zouaoui et al. (2011) for some European countries using consumer sentiment as sentiment proxy. Also, Papapostolou et al. (2016) support the significance of supertanker industry sentiment as a contrarian global predictor of financial assets in both in-sample and out-of-sample frameworks. Han and $\mathrm{Li}$ (2017) argue that China's investor sentiment is a regular momentum signal at a monthly rate both in and out of the sample. They use a sentiment index based on Baker and Wurgler's (2007) method. Other researchers find proof of intraday S\&P 500 index returns predictability when using delayed half-hour investor sentiment in both in- and outof-sample analytical metrics (Sun et al., 2016).

\section{CONCLUSION}

The sentiment index measure developed in this study built upon dynamic factor modeling of several individual sentiment proxies in Europe closely tracks returns and volatility. The measure shows the spillover effect between the US and Europe, mainly during the subprime and sovereign crisis period. Investors' past psychological biases measured by this work's sentiment index are correlated with expected volatility patterns of clustering, erratic, and leverage influence on Stoxx600 returns variance. This work concludes that investor sentiment asymmetrically affects volatility during firm peaks or strong troughs of sentiment or moderate sentiment periods. However, periods of festive investor mood may drive more prominent stock price fluctuations characteristic of cluster volatility, thereby attracting retail investors more prone to sentiment shifts. Retail investors are willing to pay more, so high price fluctuations can contribute to stock rally periods.

Furthermore, this work's sentiment index is a predictor of European returns and is a valid indicator of risk aversion. Additionally, the out-of-sample forecasts on a 60 -month rolling recursive window prove that this sentiment index is significantly more accurate than the Fama and French three-factor model in anticipating excess market yields. Moreover, when restraining for recession and expansion periods, this articles' investor sentiment index provides a high relevance of predictability power. The sentiment index closely tracks the main events causing instability in stock markets and can serve as a robust financial monitoring and forecasting tool for financial service providers, regulators, and investors.

\section{AUTHOR CONTRIBUTIONS}

Conceptualization: Pedro Manuel Nogueira Reis, Carlos Pinho.

Data curation: Pedro Manuel Nogueira Reis, Carlos Pinho.

Formal analysis: Pedro Manuel Nogueira Reis, Carlos Pinho.

Funding acquisition: Pedro Manuel Nogueira Reis, Carlos Pinho.

Investigation: Pedro Manuel Nogueira Reis, Carlos Pinho.

Methodology: Pedro Manuel Nogueira Reis, Carlos Pinho.

Project administration: Pedro Manuel Nogueira Reis, Carlos Pinho.

Resources: Pedro Manuel Nogueira Reis, Carlos Pinho. 
Software: Pedro Manuel Nogueira Reis, Carlos Pinho.

Supervision: Pedro Manuel Nogueira Reis, Carlos Pinho.

Validation: Pedro Manuel Nogueira Reis, Carlos Pinho.

Visualization: Pedro Manuel Nogueira Reis, Carlos Pinho.

Writing - original draft: Pedro Manuel Nogueira Reis, Carlos Pinho.

Writing - review \& editing: Pedro Manuel Nogueira Reis, Carlos Pinho.

\section{ACKNOWLEDGMENT}

This work is funded by National Funds through the FCT - Foundation for Science and Technology, I.P., within the scope of the project $\operatorname{Ref}^{\mathrm{a}}$ UIDB/05583/2020. Furthermore, we would like to thank the Research Centre in Digital Services (CISeD) and the Polytechnic of Viseu for their support.

\section{REFERENCES}

1. Anusakumar, S. V., Ali, R., \& Wooi, H. C. (2017). The effect of investor sentiment on stock returns: insight from emerging Asian markets. Asian Academy of Management Journal of Accounting \& Finance, 13(1), 159-178. Retrieved from https://econpapers. repec.org/article/usmjournl/ aamjaf01301_5f159-178.htm

2. Asem, E., Chung, J., Cui, X., \& Tian, G. Y. (2016). Liquidity, investor sentiment and price discount of SEOs in Australia. International Journal of Managerial Finance, 12(1), 25-51. https://doi. org/10.1108/ijmf-10-2013-0106

3. Aydogan, B. (2017). Sentiment dynamics and volatility of international stock markets. Eurasian Business Review, 7(3), 407-419. https://doi.org/10.1007/s40821016-0063-3

4. Baker, M., \& Wurgler, J. (2006). Investor sentiment and the crosssection of stock returns. Journal of Finance, 61(4), 1645-1680. https://doi.org/10.1111/j.15406261.2006.00885.x

5. Baker, M., \& Wurgler, J. (2007). Investor sentiment in the stock market. Journal of Economic Perspectives, 21(2), 129-152. Retrieved from https://www. aeaweb.org/articles?id=10.1257/ jep.21.2.129

6. Baker, M., Wurgler, J., \& Yuan, Y. (2012). Global, local, and contagious investor sentiment. Journal of Financial Economics, 104(2),
272-287. https://doi.org/10.1016/j. jfineco.2011.11.002

7. Baur, D. G., \& McDermott, T. K. (2010). Is gold a safe haven? International evidence. Journal of Banking \& Finance, 34(8), 18861898. https://doi.org/10.1016/j. jbankfin.2009.12.008

8. Beer, F., Hamdi, B., \& Zouaoui, M. (2018). Investors' sentiment and accruals anomaly: European evidence. Journal of Applied Accounting Research, 19(4), 500-517. https://doi.org/10.1108/JAAR-032017-0043

9. Benhabib, J., Liu, X., \& Wang, P. (2016). Sentiments, financial markets, and macroeconomic fluctuations. Journal of Financial Economics, 120(2), 420-443. https://doi. org/10.1016/j.jfineco.2016.01.008

10. Bolton, P., \& Jeanne, O. (2011). Sovereign default risk and bank fragility in financially integrated economies. IMF Economic Review, 59(2), 162-194. Retrieved from https://ideas.repec.org/a/pal/imfecr/v59y2011i2p162-194.html

11. Breusch, T. S. (1978). Testing for autocorrelation in dynamic linear models. Australian Economic Papers, 17(31), 334-355. https:// doi.org/10.1111/j.1467-8454.1978. tb00635. $\mathrm{x}$

12. Brown, G. W., \& Cliff, M. T. (2004). Investor sentiment and the near-term stock market. Journal of Empirical Finance, 11(1), 1-27. https://doi.org/10.1016/j.jempfin.2002.12.001
13. Chen, X., Cao, Y., \& Wang, F. (2010). A life cycle analysis of Hunan's enterprises and their determinants. China Economic Review, 21(3), 470-481. https://doi. org/10.1016/j.chieco.2010.04.006

14. Chiu, J., Chung, H., Ho, K. Y., \& Wu, C. C. (2018). Investor sentiment and evaporating liquidity during the financial crisis. International Review of Economics \& Finance, 55, 21-36. Retrieved from https://www.researchgate.net/publication/322839269_Investor_sentiment_and_evaporating_liquidity_during_the_financial_crisis

15. Chiu, J., Chung, H., Ho, K. Y., Wu, C.-Y. C. C. C., Iyer, S. R., Harper, J. T., \& Chang, J.-H. (2016). Investor sentiment and the cross-section of stock returns. Journal of Financial Economics, 49(1), 383-407. https:// doi.org/10.1287/mnsc.1110.1356

16. Da, Z., Engelberg, J., \& Gao, P. (2015). The sum of all FEARS investor sentiment and asset prices. Review of Financial Studies, 28(1), 1-32. https://doi.org/10.1093/rfs/ hhu072

17. Dash, S. R. (2016). Does investor sentiment as conditioning information help to explain stock returns behaviour? A test of alternative asset pricing models. Review of Behavioral Finance, 8(2), 174-198. https://doi.org/10.1108/ RBF-03-2014-0022

18. Debata, B., Dash, S. R., \& Mahakud, J. (2018). Investor sentiment and emerging stock 
market liquidity, Finance Research Letters, 26, 15-31. https://doi. org/10.1016/j.frl.2017.11.006

19. Dickey, D. A., \& Fuller, W. A (1979). Distribution of the estimators for autoregressive time series with a unit root. Journal of the American Statistical Association, 74(366), 427-431. https://doi. org/10.2307/2286348

20. Ding, W., Mazouz, K., \& Wang, Q. (2018). Investor sentiment and the cross-section of stock returns: New theory and evidence. Review of Quantitative Finance and Accounting, 53(2), 493-525. https:// doi.org/10.1007/s11156-0180756-Z

21. Dolado, J. J., \& Lütkepohl, H. (1996). Making Wald tests work for cointegrated VAR systems. Econometric Reviews, 15(4), 369-386. https://doi. org/10.1080/07474939608800362

22. Engle, R. F. (1982). Autoregressive conditional heteroscedasticity with estimates of the variance of United Kingdom inflation. Econometrica: Journal of the Econometric Society, 987-1007. Retrieved from https://www.jstor. org/stable $/ 1912773$ ? seq $=1$

23. Fernandes, C. M. D. A., Gonçalves, P. M. M. G., \& Vieira, E. F. S. (2013). Does sentiment matter for stock market returns? Evidence from a small European market. Journal of Behavioral Finance, 14(4), 253-267. https://doi.org/10.1 080/15427560.2013.848867

24. Gao, B., \& Yang, C. (2017). Forecasting stock index futures returns with mixed-frequency sentiment. International Review of Economics and Finance, 49, 69-83. https://doi. org/10.1016/j.iref.2017.01.020

25. Gao, Z., Ren, H., \& Zhang, B. (2020). Googling Investor Sentiment around the World. Journal of Financial and Quantitative Analysis, 55(2), 549-580. https://doi. org/10.1017/S0022109019000061

26. Giglio, S., \& Kelly, B. (2017). Excess volatility: Beyond discount rates. The Quarterly Journal of Economics, 133(1), 71-127. https:// doi.org/10.1093/qje/qjx034

27. Godfrey, L. G. (1978). Testing for higher order serial correlation in regression equations when the regressors include lagged dependent variables. Econometrica: Journal of the Econometric Society, 13031310. Retrieved from https://www. jstor.org/stable/1913830?seq=1

28. Gómez-Puig, M., Sosvilla-Rivero, S., \& del Carmen Ramos-Herrera, M. (2014). An update on EMU sovereign yield spread drivers in times of crisis: A panel data analysis. The North American Journal of Economics and Finance, 30, 133-153. https://doi.org/10.1016/j. najef.2014.09.003

29. Han, X., \& Li, Y. (2017). Can investor sentiment be a momentum time-series predictor? Evidence from China. Journal of Empirical Finance, 42, 212-23. Retrieved from https://ideas.repec.org/a/eee/ empfin/v42y2017icp212-239.html

30. He, G., Zhu, S., \& Gu, H. (2017). On the construction of Chinese stock market investor sentiment index. Cogent Economics \& Finance, 5(1). https://doi.org/10.108 0/23322039.2017.1412230

31. Ho, C., \& H. C.-H. Hung (2009). Investor sentiment as conditioning information in asset pricing. Journal of Banking and Finance, 33, 892-903. https://doi.org/10.1016/j. jbankfin.2008.10.004

32. Ho, J. C., \& Hung, C. H. (2012). Predicting stock market returns and volatility with investor sentiment: Evidence from eight developed countries. Journal of Accounting and Finance, 12(4), 49. Retrieved from https://papers.ssrn. com/sol3/papers.cfm?abstract id $=2279339$

33. Huang, D., Jiang, F., Tu, J., \& Zhou, G. (2015). Investor sentiment aligned: A powerful predictor of stock returns. Review of Financial Studies, 28(3), 791-837. Retrieved from https://academic.oup.com/ rfs/article-abstract/28/3/791/1576 380 ?redirectedFrom=fulltext

34. Huang, Y. S., \& Wang, C. J. (2015). Corporate governance and risktaking of Chinese firms: The role of board size. International Review of Economics and Finance, 37, 96-113. https://doi.org/10.1016/j. iref.2014.11.016
35. Iyer, S. R., \& Harper, J. T. (2017). Cash flow volatility and investor sentiment. Managerial Finance, 43(2), 178-192. Retrieved from http://www.fmaconferences.org/ Venice/Papers/Sentiment_and_ CFVol.pdf

36. Jitmaneeroj, B. (2017). Does investor sentiment affect price-earnings ratios? Studies in Economics and Finance, 34(2), 183-193. https:// doi.org/10.1108/sef-09-2015-0229

37. Judge, G. G., Griffiths, W. E., Hill, R. C., Lutkepohl, H., \& Lee, T.-C. 1985. The Theory and Practice of Econometrics (2nd ed.). Wiley, New York.

38. Kumari, J., \& Mahakud, J. (2015). Does investor sentiment predict the asset volatility? Evidence from emerging stock market India. Journal of Behavioral and Experimental Finance, 8, 25-39. https:// doi.org/10.1016/j.jbef.2015.10.001

39. Lee, C. M. C., Shleifer, A., \& Thaler, R. H. (1991). Investor sentiment and the closed-end fund puzzle. The Journal of Finance, 46(1), 75-109. https:// doi.org/10.1111/j.1540-6261.1991. tb03746.x

40. Lee, W. Y., Jiang, C. X., \& Indro, D. C. (2002). Stock market volatility, excess returns, and the role of investor sentiment. Journal of Banking \& Finance, 26(12), 22772299. https://doi.org/10.1016/ s0378-4266(01)00202-3

41. Loughran, T., \& McDonald, B. (2016). Textual analysis in accounting and finance: A survey. Journal of Accounting Research, 54(4), 1187-1230. https://doi. org/10.1111/1475-679X.12123

42. Lutz, C. (2016). The asymmetric effects of investor sentiment. Macroeconomic Dynamics, 20(6), 14771503. https://doi.org/10.1017/ S1365100514000996

43. Ma, C., Xiao, S., \& Ma, Z. (2018). Investor sentiment and the prediction of stock returns: a quantile regression approach. Applied Economics. Informa UK Limited, 50(50), 5401-5415. https://doi.org/ 10.1080/00036846.2018.1486993

44. Papapostolou, N. C., Pouliasis, P. K., Nomikos, N. K., \& Kyriakou, 
I. (2016). Shipping investor sentiment and international stock return predictability. Transportation Research Part E: Logistics and Transportation Review, 96, 81-94. https://doi.org/10.1016/j. tre.2016.10.006

45. Piccione, M., \& Spiegler, R. (2014). Manipulating market sentiment. Economics Letters, 122(2), 370-373. https://doi.org/10.1016/j.econlet.2013.12.021

46. Pompian, M. M. (2011). Behavioral finance and wealth management: how to build investment strategies that account for investor biases. John Wiley \& Sons. Retrieved from https://www.wiley.com/enus/Behavioral+Finance+and+Wea lth+Management $\% 3 \mathrm{~A}+\mathrm{How}+\mathrm{to}+\mathrm{B}$ uild+Investment+Strategies+That + Account + for + Investor+Biases $\% 2$ C+2nd+Edition-p-9781118182291

47. Qiu, L., \& I. Welch (2006). Investor sentiment measures (Working paper). Brown University and NBER.

48. Rehman, M. U., \& Apergis, N. (2019). Sensitivity of economic policy uncertainty to investor sentiment. Studies in Economics and Finance, 36(2), 114-129. https://doi.org/10.1108/SEF-012019-0040

49. Reijer, A. H. (2013). Forecasting Dutch GDP and inflation using alternative factor model specifications based on large and small datasets. Empirical Economics, 44(2), 435-453. Retrieved from https:// link.springer.com/article/10.1007/ s00181-012-0560-x

50. Reis, P. M. N., \& Pinho, C. (2020a). A Reappraisal of the Causal Relationship between Sentiment Proxies and Stock Returns. Journal of Behavioral Finance, 1-23. https:// doi.org/10.1080/15427560.2020.1 792910

51. Reis, P. M. N., \& Pinho, C. (2020b). A new European investor sentiment index (EURsent) and its return and volatility predictability. Journal of Behavioral and Experimental Finance, 27, 100373. https://doi.org/10.1016/j. jbef.2020.100373

52. Reis, P. M. N., \& Pinto, A. P. S. (2021). Behavioral Finance. In S.
Idowu, R. Schmidpeter, N. Capaldi, L. Zu, M. Del Baldo, \& R. Abreu (Eds), Encyclopedia of Sustainable Management. Springer, Cham. https://doi.org/10.1007/978-3-03002006-4_985-1

53. Rupande, L., Muguto, H. T., \& Muzindutsi, P.-F. (2019). Investor sentiment and stock return volatility: Evidence from the Johannesburg Stock Exchange. Cogent Economics \& Finance, 7(1). https:// doi.org/10.1080/23322039.2019.1 600233

54. Ryu, D., Kim, H., \& Yang, H. (2017). Investor sentiment, trading behavior and stock returns. Applied Economics Letters, 24(12), 826-830. https://doi.org/10.1080/1 3504851.2016 .1231890

55. Schmeling, M. (2009). Investor sentiment and stock returns: Some international evidence. Journal of Empirical Finance, 16(3), 394-408. https://doi.org/10.1016/j.jempfin.2009.01.002

56. Seok, S. I., Cho, H., \& Ryu, D. (2019). Firm-specific investor sentiment and daily stock returns. The North American Journal of Economics and Finance, 50, 100857. https://doi.org/10.1016/j.najef.2018.10.005

57. Simões Vieira, E. (2011). Investor sentiment and the market reaction to dividend news: European evidence. Managerial Finance, 37(12), 1213-1245. https://doi. org/10.1108/03074351111175100

58. Smales, L. A. (2017). The importance of fear: Investor sentiment and stock market returns. Applied Economics, 49(34), 3395-3421. https://doi.org/10.1080/00036846. 2016.1259754

59. StataCorp. (2019). Stata Statistical Software: Release 16. StataCorp LLC, College Station, TX.

60. Stock, J. H., \& Watson, M. (2011). Dynamic factor models. Oxford handbook on economic forecasting.

61. Stock, J. H., \& Watson, M. W. (1989). New indexes of coincident and leading economic indicators. NBER macroeconomics annual, 4 , 351-394. Retrieved from https:// www.nber.org/system/files/chapters/c10968/c10968.pdf
62. Stock, J. H., \& Watson, M. W. (1998). Business cycle fluctuations in US macroeconomic time series. National Bureau of Economic Research. Retrieved from https:// www.nber.org/papers/w6528

63. Stock, J. H., \& Watson, M. W. (2002). Forecasting using principal components from a large number of predictors. Journal of the American Statistical Association, 97(460), 1167-1179. Retrieved from https://www.jstor. org/stable/3085839? seq $=1$

64. Stock, J. H., \& Watson, M. W. (2016). Dynamic factor models, factor-augmented vector autoregressions, and structural vector autoregressions in macroeconomics. Handbook of Macroeconomics, 2, 415-525. Elsevier. Retrieved from https://ideas.repec.org/h/eee/ macchp/v2-415.html

65. Sudha, S. (2015). Risk-return and volatility analysis of sustainability index in India. Environment, Development and Sustainability, 17(6), 1329-1342. Retrieved from https:// link.springer.com/article/10.1007/ s10668-014-9608-8

66. Toda, H. Y. \& Yamamoto (1995). Statistical inference in Vector Autoregressions with possibly integrated processes. Journal of Econometrics, 66, 225-250. Retrieved from https://econpapers. repec.org/article/eeeeconom/ v_3a66_3ay_3a1995_3ai_3a12_3ap_3a225-250.htm

67. Tsai, I. C. (2017). Diffusion of optimistic and pessimistic investor sentiment: An empirical study of an emerging market. International Review of Economics and Finance, 47, 22-34. https://doi.org/10.1016/j. iref.2016.10.008

68. Watson, M. W., \& Engle, R. F. (1983). Alternative algorithms for the estimation of dynamic factor, mimic and varying coefficient regression models. Journal of Econometrics, 23(3), 385-400. Retrieved from https://www. princeton.edu/ mwatson/papers/ Engle_Watson_JoE_1983.pdf

69. White, H. (1980). A heteroskedasticity-consistent covariance matrix estimator and a direct test for heteroskedasticity. Econo- 
metrica, 48(4), 817. https://doi. org/10.2307/1912934

70. Wu, Y., Liu, T., Han, L., \& Yin, L. (2018). Optimistic bias of analysts earnings forecasts: Does investor sentiment matter in China? Pacific Basin Finance Journal, 49, 147-163. https://doi.org/10.1016/j. pacfin.2018.04.010

71. Yang, C., \& Zhou, L. (2015). Investor trading behavior, investor sentiment and asset prices. North American Journal of Economics and Finance, 34, 42-62. https://doi. org/10.1016/j.najef.2015.08.003

72. Yang, C., \& Zhou, L. (2016). Individual stock crowded trades, individual stock investor sentiment and excess returns. North
American Journal of Economics and Finance, 38, 39-53. https://doi. org/10.1016/j.najef.2016.06.001

73. Yang, C., \& Zhou, L. (2015). Investor trading behavior, investor sentiment and asset prices. The North American Journal of Economics and Finance, 34, 42-62. https://doi. org/10.1016/j.najef.2015.08.003

74. Yang, C., \& Zhou, L. (2016). Individual stock crowded trades, individual stock investor sentiment and excess returns. The North American Journal of Economics and Finance, 38, 39-53. https://doi. org/10.1016/j.najef.2016.06.001

75. Zhou, G. (2018). Measuring investor sentiment. Annual Review of Finance Economics, 10, 239-259. https://doi.org/10.1146/annurevfinancial-110217-022725

76. Zhou, L., \& Yang, C. (2019). Investor sentiment, investor crowdedtrade behavior, and limited arbitrage in the cross section of stock returns. Empirical Economics, 1-24. https://doi.org/10.1007/ s00181-019-01630-7

77. Zouaoui, M., Nouyrigat, G., \& Beer, F. (2011). How does investor sentiment affect stock market crises? Evidence from panel data. Financial Review, 46(4), 723-747. Retrieved from https://www.researchgate.net/ publication/227710094_How_ Does_Investor_Sentiment_Affect_Stock_Market_Crises_Evidence_from_Panel_Data 